\title{
Physical Mechanisms Regulating Summertime Rainfall over Northwestern Australia
}

\author{
Gareth BerRy, Michael J. ReEder, And Christian JAKOB \\ Monash Weather and Climate, Monash University, Clayton, Victoria, Australia
}

(Manuscript received 28 July 2010, in final form 20 February 2011)

\begin{abstract}
Summertime (December-February) rainfall over northwestern Australia has increased significantly since the middle of the twentieth century. As a prerequisite to understanding the observed trend, this investigation examines the broad characteristics of rainfall and identifies the physical mechanisms by which rainfall in the region is initiated. This is achieved using a combination of in situ, spaceborne, and numerical reanalysis datasets.

Hourly pluviograph data and the Tropical Rainfall Measuring Mission (TRMM)-3B42 dataset show distinctly different diurnal cycles of rainfall in different geographical subregions; near the coast, rainfall rates peak in the midafternoon, whereas inland (near the maximum rainfall trend) the rainfall rate is largest overnight. These data also indicate that most of the summertime rain falls in events lasting $2-5$ days. Analysis of the ECMWF Re-Analysis (ERA-Interim) demonstrates that convergence into the continental heat low controls the diurnal cycle of rainfall but cannot explain the synoptic variability.

Composites of wet and dry conditions from ERA-Interim expose synoptic-scale differences in the environmental flow. Prior to rain falling in the interior of northwestern Australia, there is a distinct shift in the origins of low-level air parcels, such that air with high convective available potential energy is advected from the tropical maritime regions, rather than from over the continent. Preliminary analysis suggests that these flow changes may be linked to transient synoptic disturbances such as midlatitude cyclones and monsoon lows. Rather than reflecting a large-scale change in the ocean state, these results imply that the observed increase in rainfall may be linked more closely to changes in the synoptic weather systems.
\end{abstract}

\section{Introduction}

Recent studies of rainfall trends over the Australian continent have noted a significant increase in summertime [December-February (DJF)] rainfall over northwestern Australia (NWA) during the last half century or so (e.g., Smith 2004). Figures $1 \mathrm{a}$ and 1 b, which are based on rainfall data from the Australian Bureau of Meteorology (BOM; see Lavery et al. 1992), show the December-February mean rainfall and its linear trend for the period 1950-2008. A large positive trend exists across much of NWA, which is maximized a few hundred kilometers inland of the coast. In the literature there are diverse explanations for this trend, including increasing anthropogenic aerosols in the Northern Hemisphere (Rotstayn et al. 2007), changes in regional sea surface temperatures (Shi et al. 2008), land surface changes (Wardle and Smith 2004), and changes in the

Corresponding author address: G. Berry, Monash University, Weather and Climate, Building 28, Clayton, VIC 3800, Australia. E-mail: gareth.berry@monash.edu
Australian monsoon onset (Taschetto and England 2008).

The region of maximum positive trend in Fig. $1 \mathrm{~b}$ is located in a region of a strong gradient in the mean rainfall (Fig. 1a), separating the monsoon region (Wheeler and McBride 2005) and the desert interior of the continent. The displacement of the maximum trend away from the area of maximum rainfall cannot be explained by an increase in the intensity of monsoon rainfall. In fact, the maximum positive trends lie along the axis of the heat trough shown by the DJF mean sea level pressure displayed in Fig. 1c (cf. Spengler et al. 2005). This collocation suggests a connection between this ubiquitous feature of the summertime climate and the regional rainfall, including perhaps, the rainfall trends. While there are few works describing how heat lows initiate rainfall, they are thought to play a part in driving the monsoon (e.g., Hall and Peyrille 2006). In the context of Northern Australia, Racz and Smith (1999) presented an idealized model of a heat low and commented that nocturnal convergence in the center of the heat low was connected with the casual observations of 

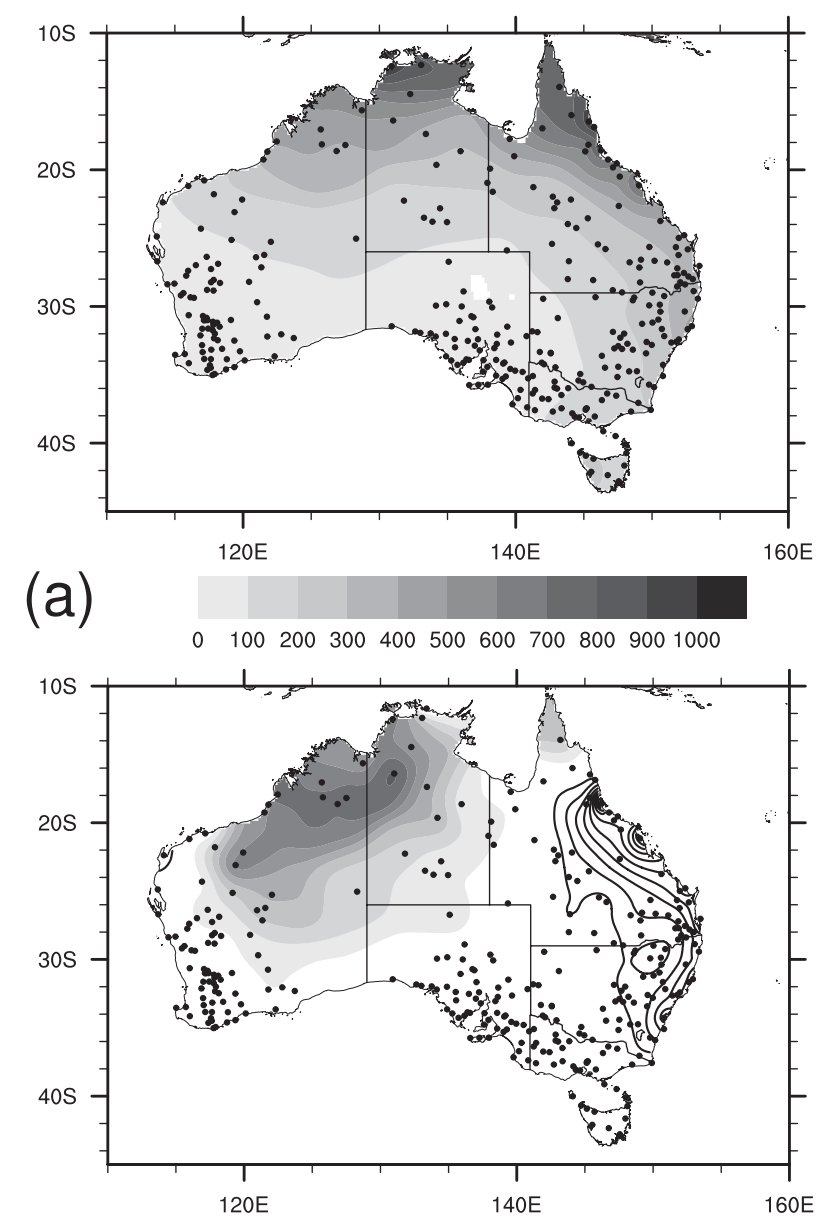

(b)

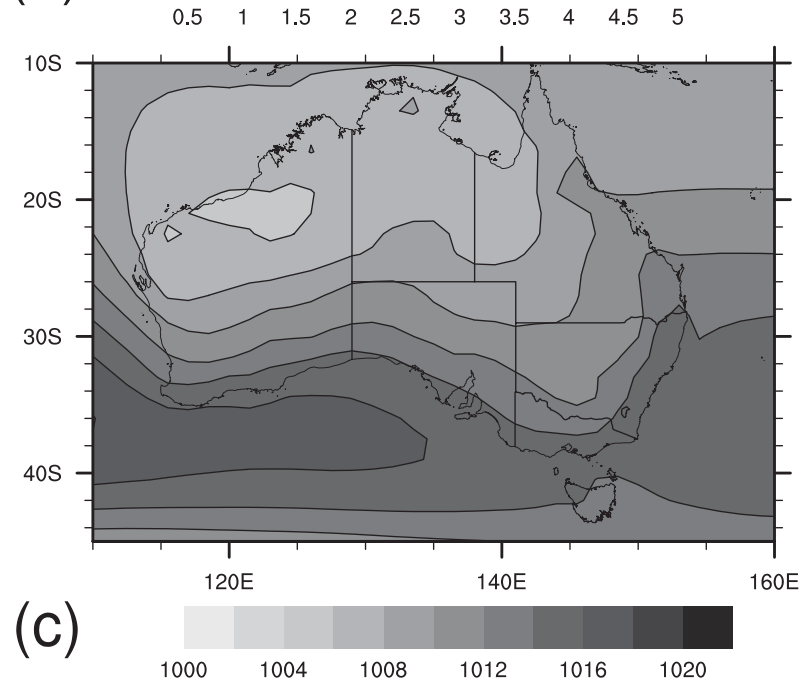

FIG. 1. (a) Mean December-February rainfall (mm, shaded according to legend) and (b) linear trend of rainfall $\left(\mathrm{mm} \mathrm{yr}^{-1}\right.$, positive values shaded according to legend, negative values contoured every $0.5 \mathrm{~mm} \mathrm{yr}^{-1}$ below $-0.5 \mathrm{~mm} \mathrm{yr}^{-1}$ ) for the period $1950-2008$. Data are from the BOM high-quality daily rainfall dataset (see Lavery et al. 1992). Locations of the climate stations used are marked by black circles. (c) Mean sea level pressure (hPa) at 1200 UTC (2000 LT), averaged during December-February for the period 1989-2008 from the ERA-Interim dataset. nighttime thunderstorms in the center of the Australian heat low. Arnup and Reeder $(2007,2009)$ examined the diurnal rearrangement of the low-level flow over Australia, showing that a dryline developed as a result of the inland advection of maritime air and ageostrophic convergence into the heat low, forming a dynamical focus for convection. Although the maximum rainfall trend and heat low are collocated the physical links between the heat low dynamics and rainfall have not been established.

Although the rainfall trend is well described in NWA, there are few studies that describe the frequency, intensity, and timing of the rainfall in this region and the fundamental physics that regulate it on weather time scales. Understanding the physical mechanisms by which rainfall is initiated is a prerequisite to understanding how it is changing in NWA. It is argued here that this current lack of knowledge inhibits our ability to correctly identify the main forcings of the observed rainfall trend and may explain why there is little consensus about its cause. The core aim of the research presented here is to examine the spatiotemporal variability of precipitation in NWA to expose the dominant dynamic or thermodynamic mechanisms controlling it. In particular, the study seeks to determine whether rainfall is controlled more strongly by dynamic triggers (e.g., convergence into the heat low) or by the thermodynamic conditions of the large-scale environment.

The research presented here is divided into five sections. Section 2 describes the datasets used and the methodology employed. Section 3 presents the main results, which are then discussed in section 4 . The conclusions and suggestion for future research are given in section 5 .

\section{Datasets and methodology}

Pluviograph records (hourly observations of rainfall amounts) from several BOM sites in NWA form the basis of the analysis in this study. The temporal distribution of rainfall during DJF is analyzed from these data. Four stations are selected for detailed analysis, the locations of which are marked on a topographic map in Fig. 2a. Other relevant information about each pluviograph site is listed in Table 1. These particular sites have been selected as they all have long data records (in excess of $30 \mathrm{yr}$; see Table 1) and form a $700 \mathrm{~km}$ long line from the coast through the center of the continental heat low region (see Fig. 1c) and the region of maximum rainfall increase (Fig. 1b). Differences in local surface properties are summarized by the December-February mean normalized difference vegetation index (NDVI; Tarpley et al. 1984) shown in Fig. 2b, which is a satellite estimate of the amount of vegetation. Clearly, the amount 


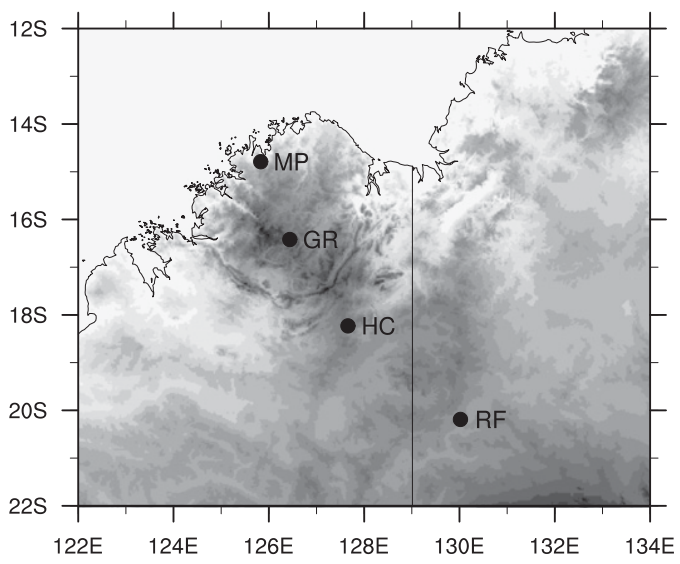

(a)

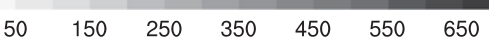

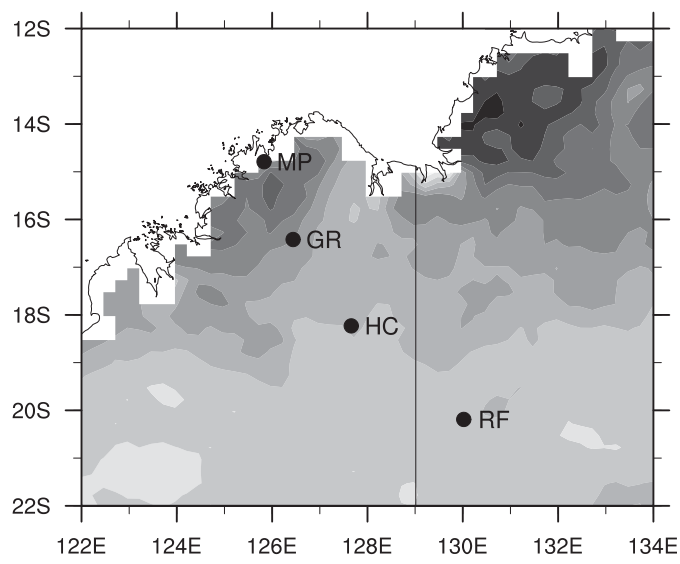

(b)

FIG. 2. (a) Topographic map (m) for the region surrounding the BOM pluviographs used in this analysis. (b) DecemberFebruary mean NDVI. The location of BOM pluviograph sites are denoted by filled circles and abbreviations, where $\mathrm{MP}=$ Mitchell Plateau, GR $=$ Gibb River, $\mathrm{HC}=$ Halls Creek, and RF $=$ Rabbit Flat.

of vegetation decreases from the coast into the interior of the continent, reflecting the summertime total precipitation shown in Fig. 1a.

Although tropical cyclones are relatively infrequent, they are certainly an important component of the climate of NWA (e.g., McBride and Keenan 1982) and can have a large effect on the rainfall record at a particular location. Since the aim of this research is to uncover the general mechanisms controlling rainfall, the effect of tropical cyclones is not directly addressed. Consequently, based on the International Best-Track Archive for Climate Stewardship (IBTrACS) tropical cyclone dataset (Knapp et al. 2009), all periods in which there is a tropical cyclone within $10^{\circ}$ of the BOM sites are removed from the analysis. This removes less than $1 \%$ of the pluviograph records in DJF.

From preliminary analysis of the pluviograph datasets it was determined that approximately $50 \%$ of the nonzero hourly rainfall values were recorded as $0.1 \mathrm{~mm} \mathrm{~h}^{-1}$. Because this amount is lower than the expected measurement accuracy and the integrated rainfall from such records contribute less than $5 \%$ of the total, they are assumed to be trace values and are completely removed from the analysis. Table 1 summarizes the key aspects of the rainfall records at each station, including the percentage of missing and trace data.

To investigate the characteristics of summertime rainfall on larger spatial scales satellite rainfall estimates provided by the Tropical Rainfall Measuring Mission (TRMM) 3B42 merged infrared product (Huffman et al. 2007) are used. This dataset is generated by merging infrared observations from geostationary satellites with microwave and brightness temperature data from the polar-orbiting TRMM platform using a monthly mean gauge-calibrated rainfall algorithm. These data are available every $3 \mathrm{~h}$ for the period 1998-2008 with a spatial resolution of $0.25^{\circ} \times 0.25^{\circ}$ from $60^{\circ} \mathrm{S}$ to $60^{\circ} \mathrm{N}$.

The European Centre for Medium-Range Weather Forecasts (ECMWF) Re-Analysis (ERA-Interim) dataset (ERA-I) is utilized to understand the atmospheric patterns associated with rainfall in the region. These data are provided on a $1.5^{\circ} \times 1.5^{\circ}$ horizontal grid with 37 vertical pressure levels for the period 1989-2008. For each of the four BOM pluviograph sites a composite of ERA-I is constructed using only those days on which no rainfall was recorded over a 24-h period (0000-0000 LT, 0800-0800 UTC). Such a composite will be called a dry composite hereafter. The corresponding wet composite is constructed using days in which there was nonzero rainfall over a 24-h period (0000-0000 LT). In instances where rain falls on consecutive days, only the first day is used in the composite because the aim is to determine the conditions at the time that rainfall is initiated rather than the atmospheric response to rainfall and convection. In both composites, the individual analysis times comprising the 24-h period are composited separately to retain information about the diurnal cycle in the atmospheric fields.

The ocean state is examined using the National Oceanographic and Atmospheric Administration (NOAA) optimum interpolation (OI) sea surface temperature (SST) dataset (Reynolds et al. 2002), which is comprised of weekly means available from 1981 to the present on a $1^{\circ}$ global grid. In a manner similar to that used with the ERA-I dataset, wet and dry composites for each site are constructed based on the BOM pluviographs. 


\section{Results}

\section{a. Rainfall characteristics}

The mean diurnal cycle of rainfall from the pluviograph data, expressed as a percentage of the daily mean, at each of the four BOM sites is shown in Fig. 3a. There is a significant difference in the diurnal cycle of rainfall between the coastal and interior regions. In particular, the records at the coastal site, Mitchell Plateau (MP), show a pronounced peak in the afternoon hours (between 1200 and 1800 LT), whereas at the southernmost site, Rabbit Flat (RF), the precipitation is spread more broadly over the nighttime hours (1800-0600 LT). At Gibb River (GR), the maximum rainfall rate occurs near $1600 \mathrm{LT}$, but the peak there is not as prominent as at the coastal station, with a large proportion of the rain falling overnight. At Halls Creek (HC), there are multiple peaks in the mean rainfall rate, one near $1600 \mathrm{LT}$ and another during the overnight hours. Broadly speaking, near the coast (MP) the rainfall rate peaks in the afternoon and early evening, far inland (RF) the rainfall rate peaks in the early hours of the morning, and in between (GR and HC) the rainfall rate shares the characteristics of both the coastal and interior sites.

The tendency for the rainfall to occur more frequently in the overnight hours inland is summarized in Fig. 3b, which shows a bar graph of the mean precipitation rate at each station with the nocturnal (1800-0600 LT) contribution overlaid. As expected from the mean rainfall in Fig. 1a, the largest totals fall at the station closest to the coast, but it is evident here that the nocturnal fraction of rainfall increases further inland. In the region of the heat trough, where climatologically the rainfall has increased the most (see Fig. 1), more than half the rain falls overnight.

The mean diurnal cycle in DJF from the TRMM 3B42 precipitation dataset is shown in Fig. 3c at the grid points closest to the four BOM sites. Comparing the equivalent figure from the pluviographs (Fig. 3a) to the TRMM rainfall estimate shows that they are highly correlated; the diurnal cycles are essentially the same at all four locations in both datasets. Note that there is a factor of 3 difference in the magnitudes as the TRMM dataset comprises 3-h totals, whereas the pluviograph dataset comprises 1-h totals. Although the TRMM 3B42 algorithm incorporates rain gauge data in its calibration, only monthly accumulated values are used (Huffman et al. 2007) and, therefore, the similarity between diurnal cycles is a not determined by the calibration process. The overall consistency between datasets suggests that (i) the pluviograph stations are representative of the diurnal cycle behavior in the region and (ii) the TRMM 3B42 dataset is suitable for 

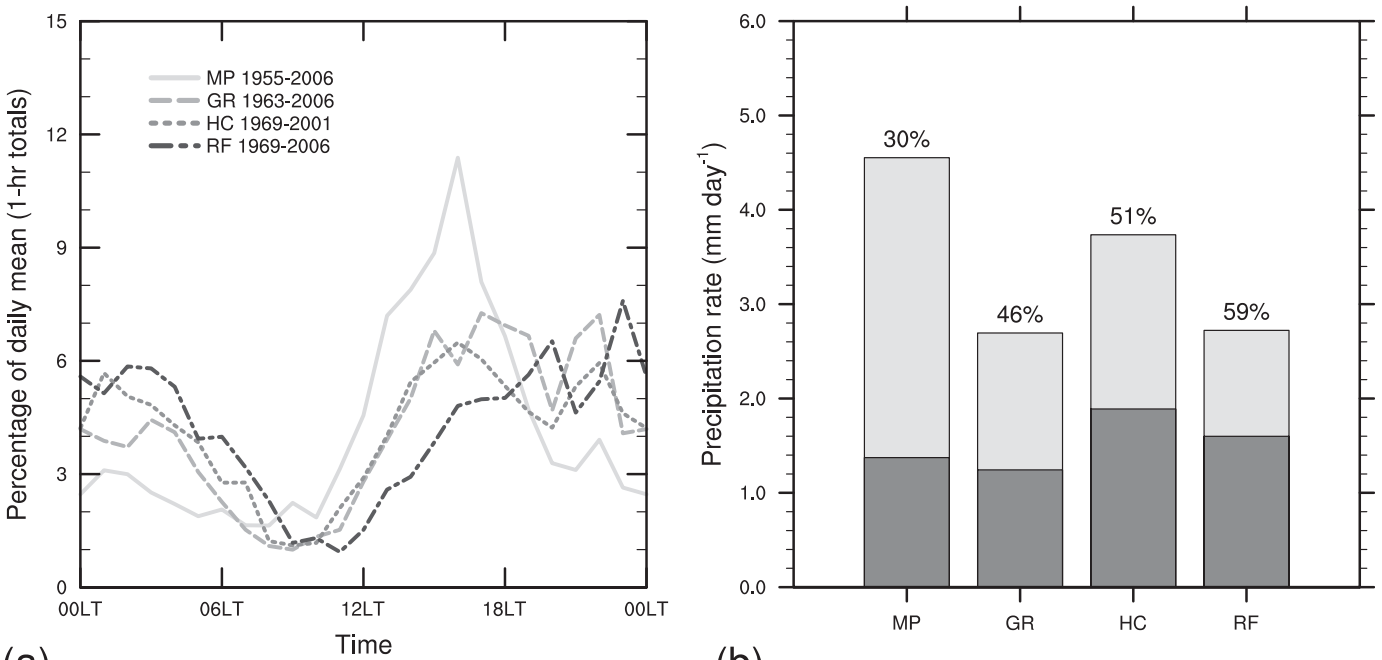

(a)

(b)
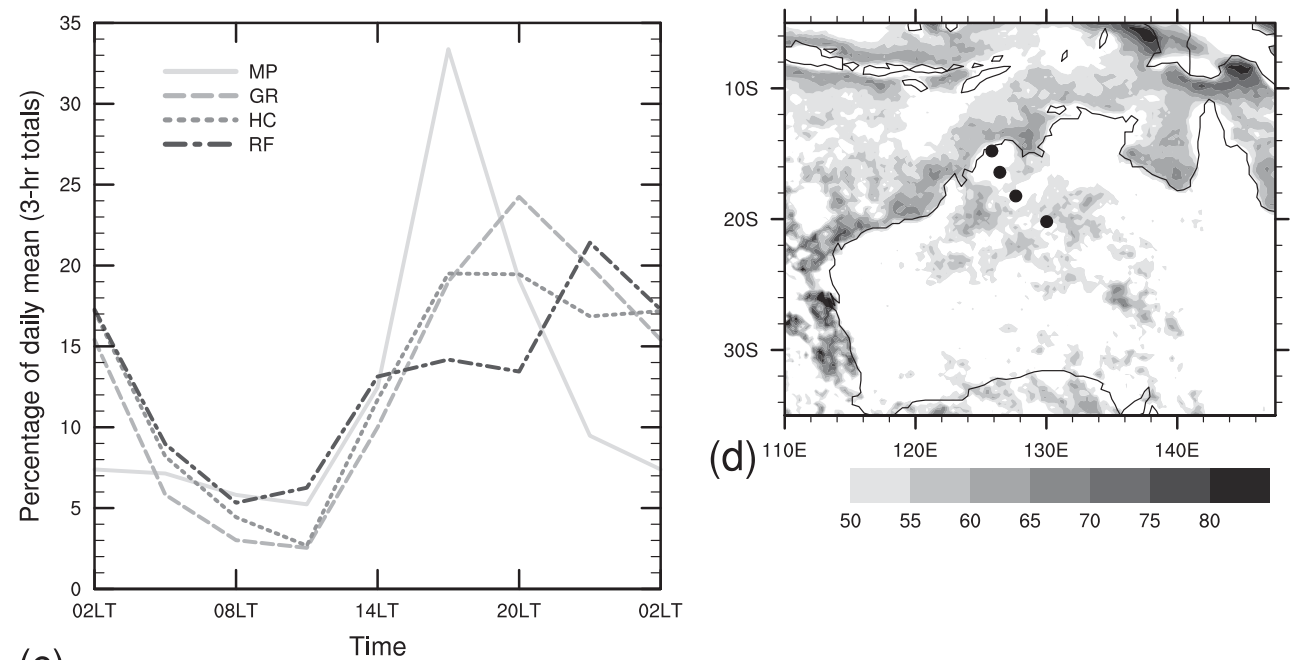

(c)

FIG. 3. (a) Mean diurnal cycles of rainfall rate during December-February, expressed as a percentage of the daily mean, derived from BOM pluviograph data. (b) Average rainfall rate at each of BOM pluviograph with overnight fraction (1800-0600 LT) indicated by dark shading. The percentage contribution from nocturnal rainfall at each site is annotated at the top of each bar. (c) As in (a), but showing 3-hourly contribution from the TRMM 3B42 dataset at closest grid point to pluviograph sites. Note that the percentages are expressed as 3-h totals. (d) Map of the percentage of total TRMM 3B42 rainfall recorded during the overnight (1800-0600 LT) hours during DecemberFebruary. The locations of the four BOM pluviograph sites are marked by black dots.

examining the diurnal cycle over a large region. Consequently, the percentage of mean DJF TRMM 3B42 estimated rainfall occurring during the overnight period (defined here as 2000-0800 LT, 1200-0000 UTC) is shown on a map in Fig. 3d. The TRMM data reveal that in NWA there is a large region near the BOM pluviograph sites where the majority of the rainfall is nocturnal. The size and orientation of this region is similar to that of the midafternoon heat trough over NWA (Fig. 1c) and closely matches the area of positive rainfall trends shown in Fig. 1b.
Power spectra are commonly used to analyze data and detect features on time scales longer than a day (see, e.g., Wheeler and McBride 2005). In the case of the BOM pluviograph data there are a significant number of missing or removed values (see Table 1), and consequently such methods are not technically feasible without the fabrication of data. Instead, the characteristics of rainfall on longer time scales are considered in terms of episodes, which are quantified by calculating the length of each rainfall event. Rather than calculating the number of hours of consecutive rainfall, which reflects 

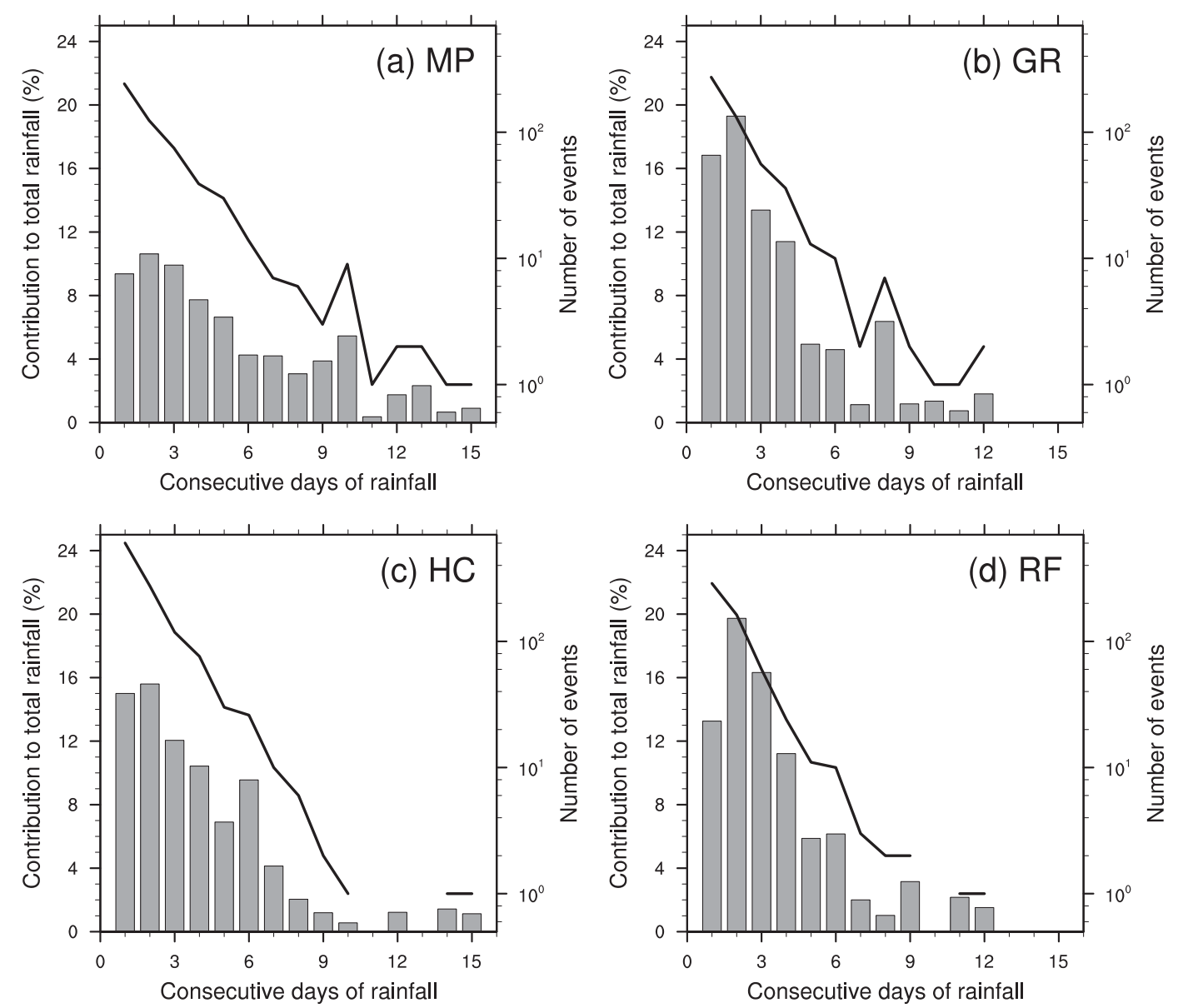

FIG. 4. Histograms showing the percentage contribution to the total from rainfall events lasting a specific number of consecutive 24-h periods at each BOM pluviograph location. The number of events is overlaid as a line with the number indicated along the right axis.

the time scale of an individual thunderstorm, the length of a precipitation event is defined as the number of consecutive 24-h periods [starting at 0800 UTC (local midnight)] in which there is measurable precipitation.

The number of events at each site and their percentage contribution to the total rainfall are shown in Fig. 4. At all sites, approximately half the events last no more than $24 \mathrm{~h}$, consistent with relatively short-lived convective systems (e.g., individual convective cells) rather than convection that is persistently forced (e.g., by the presence of a monsoon low). The number of events decays exponentially with the number of consecutive days of rainfall; the slowest decay rate occurs at MP and the fastest at RF, consistent with the mean precipitation totals (e.g., Figure 1a). At the two stations closest to the coast (MP and GR, Figs. 4a,b) there is a peak in the number of events lasting between 9 and 11 days, which could be a signal of the active periods of the Australian monsoon (e.g., Hendon and Liebmann 1990). The contribution to the total rainfall from events of different duration (plotted as bars in Fig. 4) shows that although events lasting 1 day are the most numerous, they do not make the largest contribution to the total rainfall. At all locations the largest percentage of the total rainfall comes from events lasting 2 days. At MP the contributions from events lasting between 1 and 10 days are comparable, with each time scale contributing between $3 \%$ and $11 \%$ of the total rainfall. At the other three locations, approximately $50 \%$ of the total rainfall occurs within events lasting between 2 and 5 days. This time scale falls within the synoptic scale and strongly suggests that processes that occur on these scales [e.g., subtropical fronts, monsoon depressions (Hell and Smith 1998), land surface feedbacks (see Taylor and Lebel 1998)] could significantly influence the variability of the rainfall in this region.

\section{b. Composite analysis}

The thermodynamic and dynamic processes initiating summertime rainfall in NWA are considered now using 

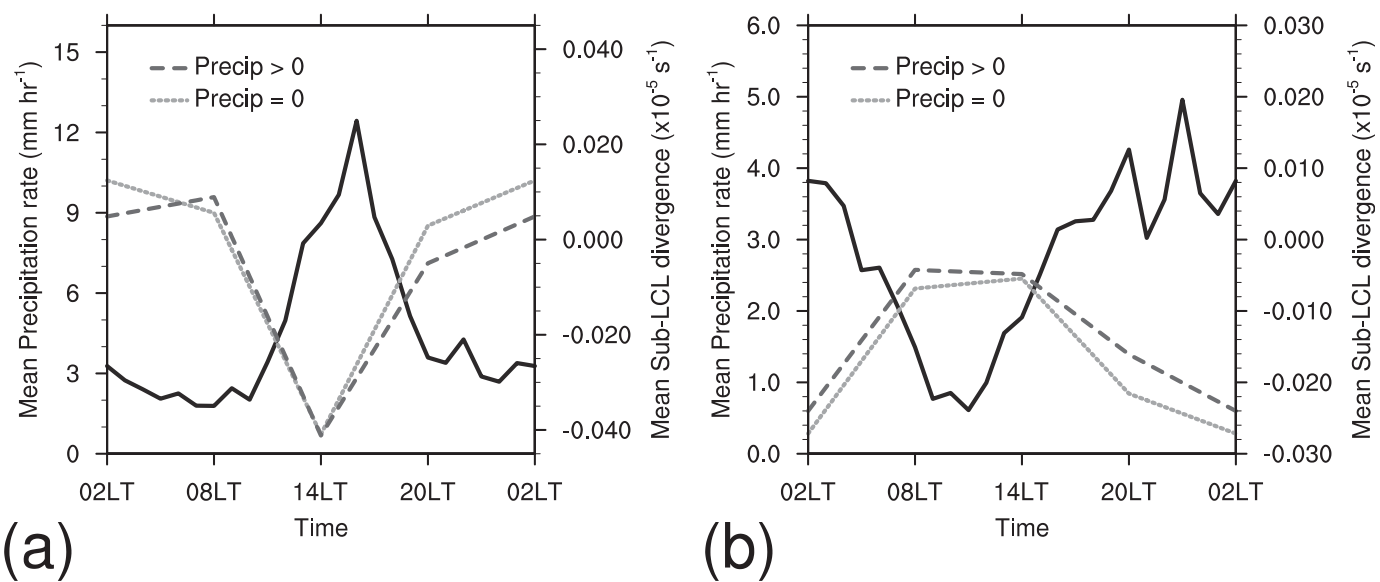

FIG. 5. Time series of mean pluviograph rainfall (solid line, left axis) and ERA-Interim composite divergence below the lifting condensation level of an air parcel originating from $1000 \mathrm{hPa}$ (dashed line according to legend, right axis) at (a) MP and (b) RF.

composites constructed using the ERA-I reanalysis. First, the data are used to determine if the diurnal cycle of rainfall at each site can be attributed to the diurnal cycle of the heat low and its associated circulation. Second, the nature of the large-scale environment, including its thermodynamic structure, is considered.

Figure 5 shows the composite diurnal cycles of divergence below the cloud-lifting condensation level (computed using the 1000-hPa temperature and moisture values) at the grid points closest to MP and RF, with the BOM pluviograph rainfall diurnal cycles overlaid. For brevity, only the northernmost and southernmost sites (MP and RF) are shown. The results for the intermediate stations (GR and $\mathrm{HC}$ ) are essentially the same as at the southernmost site (RF). In both locations the diurnal maximum in rainfall coincides with the daily peak in low-level convergence, which is consistent with the hypothesis that the timing of rainfall is dictated by the diurnal cycle. However, the magnitude of this lowlevel convergence is essentially the same in the wet and dry composites at both sites, implying that convergence is not the factor limiting the rainfall. Based on this, it appears that if rainfall occurs on a given day, the timing is determined by the local diurnal cycle of convergence within the heat low, but other processes must control whether or not rainfall actually occurs.

The low-level convergence in the heat low appears as a necessary but not sufficient condition for the initiation of rainfall in this region; therefore, it is likely that the observed rainfall trends are more related to long-term changes in the large-scale environment, rather than the nature of this convergence.

The role of the large-scale environment is explored using Fig. 6, which shows the daily averaged 1000-900-hPa mean geopotential height and winds in both the wet and dry composites for MP (left column) and RF (right column). For clarity, the differences (wet minus dry) between the composites are shown also in Figs. $6 \mathrm{c}$ and $6 \mathrm{f}$. In both locations the continental-scale atmospheric state is similar in the composites; the NWA region is dominated by a broad heat low (defined by an enclosed region of low geopotential heights) and the associated cyclonic circulation that is oriented parallel to the northwestern coastline with the geopotential height minima located approximately $500 \mathrm{~km}$ inland. Within the heat low there are two relative minima, one over the Top End peninsula of the Northern Territory, east of the BOM sites (approximately $16^{\circ} \mathrm{S}, 132^{\circ} \mathrm{E}$ ) and the other to the west of the BOM sites near $20^{\circ} \mathrm{S}, 122^{\circ} \mathrm{E}$. These minima occur over the Tanami and Great Sandy Deserts, with the BOM pluviograph sites between.

The difference plots (Figs. 6c,f) indicate that the onset of rainfall at MP and RF is accompanied by a large-scale difference in the heat low structure and further analysis (not shown) indicates that these differences are present throughout the lower troposphere. At MP, the geopotential heights are lower across the entire heat low region, with the largest differences located far to the east of MP, near the Gulf of Carpentaria. The geopotential height difference is associated with an increase in the westerly (onshore) component of the flow at MP and an increased southerly component just inland. At RF (Fig. 6f), the onset of rainfall is associated with decreased geopotential heights to the southwest of the site, with little difference elsewhere. The anomalous cyclonic circulation associated with this geopotential height difference results in a marked northwesterly flow difference at RF at the onset of rainfall, although the total flow (Fig. 6d) is from the north and east. 


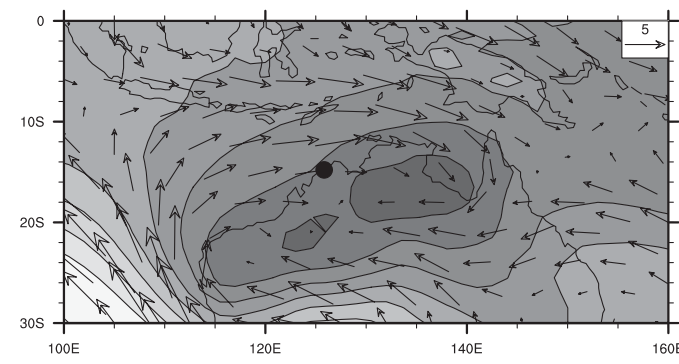

(a)

$480 \quad 490 \quad 500 \quad 510 \quad 520 \quad 530540550 \quad 560 \quad 570 \quad 580$

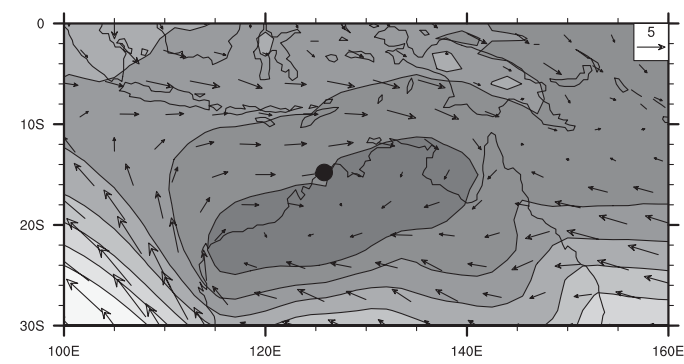

(b)

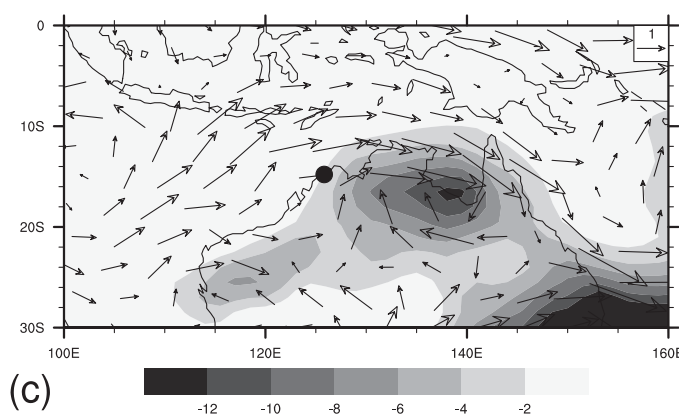

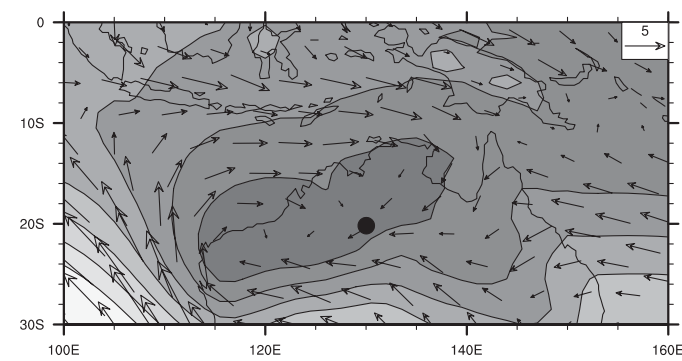

(d)

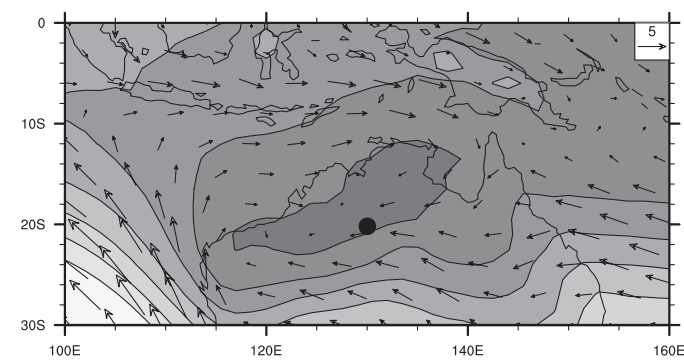

(e)

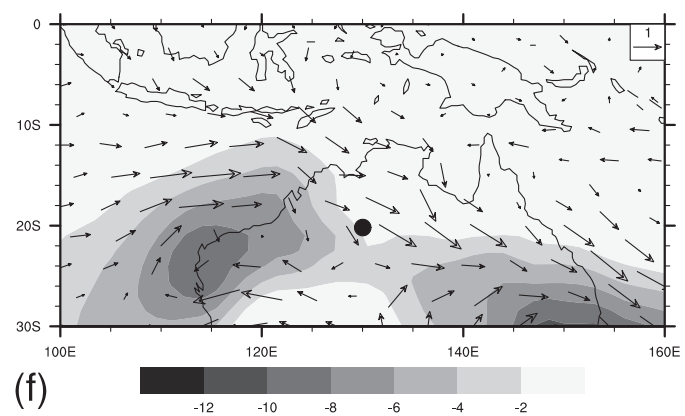

FIG. 6. Composite ERA-Interim fields based on pluviograph records: daily mean 1000-900-hPa geopotential height ( $\mathrm{m}$, shading) and wind vectors ( $\mathrm{m} \mathrm{s}^{-1}$, reference vector in the top-right corner of each panel) for (a) the start of rainfall events and (b) during dry periods at MP. (c) The difference between the wet and dry composites (wet minus dry) at MP. For the geopotential height difference (m), only negative values shown (shaded every $2 \mathrm{~m}$ ). (d)-(f) As in (a)-(c), but for composites based on pluviograph at RF. The locations of the pluviograph sites are designated by black dots.

Given the large-scale changes in the lower-troposphere flow that occur prior to the initiation of rainfall and the strong environmental gradients of temperature and moisture over NWA, it is likely that there are substantial changes in the thermodynamic structure at specific locations. Changes in the vertical profiles of temperature and moisture will modulate atmospheric stability and affect the rainfall by changing the probability or strength of convection. To quantify this, convective available potential energy (CAPE) in the wet and dry composites are compared. Figure 7 shows the difference in pseudoadiabatic CAPE for parcel ascents originating from $950 \mathrm{hPa}$ between the wet and dry composites. In the MP composites there is very little difference in CAPE between composites, with the mean values at MP (not shown) in both being relatively high (approximately
$1000 \mathrm{~J} \mathrm{~kg}^{-1}$ ). There is a large area in which the difference is negative located just offshore, resulting from the advection of relatively cool and dry air at low levels.

In the RF composites (Fig. 7b), precipitation is preceded by a very large (up to $1000 \mathrm{~J} \mathrm{~kg}^{-1}$ ), widespread increase in pseudoadiabatic CAPE. Further analysis (not shown) indicates that both slight cooling and strong moistening of the troposphere below $700 \mathrm{hPa}$ causes this change in CAPE prior to the onset of the rainfall. This pattern of increased CAPE in the RF composite is very similar to that for the remaining inland BOM sites (consistent with the composite atmospheric structures being very similar) but highly dissimilar to MP. This reinforces the earlier conclusion from the analysis of the pluviograph records that the large-scale mechanisms 

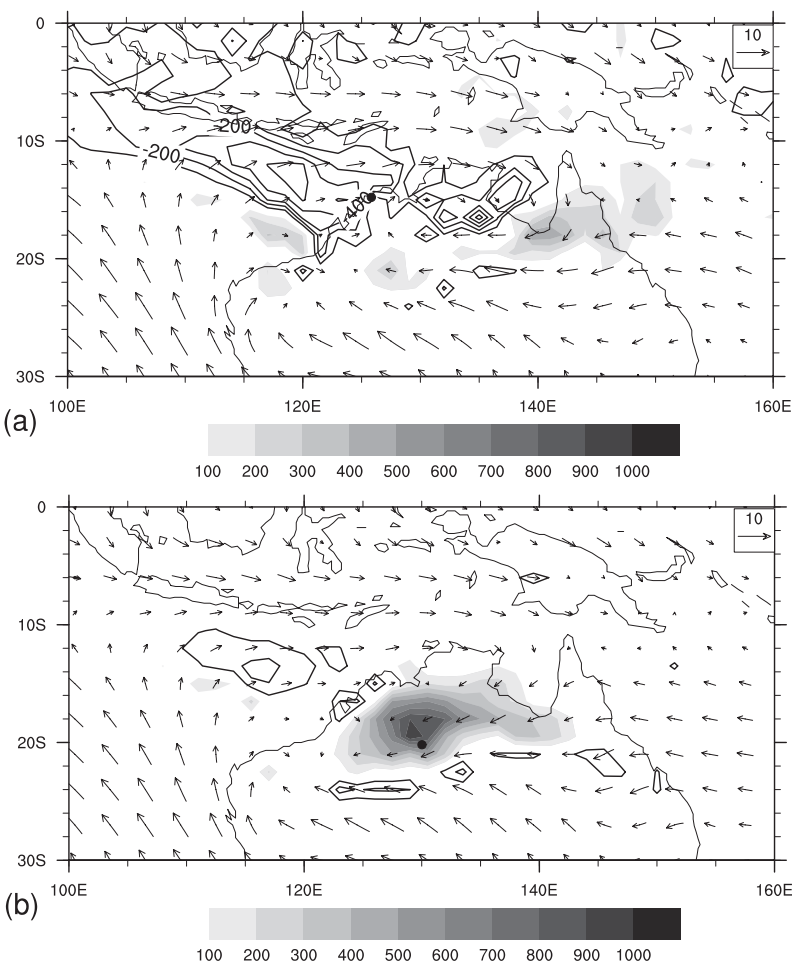

FIG. 7. Wet minus dry composite difference in daily average pseudoadiabatic CAPE for parcel ascending from $950 \mathrm{hPa}\left(\mathrm{J} \mathrm{kg}^{-1}\right.$, positive values shaded according to legend and negative values contoured every $100 \mathrm{~J} \mathrm{~kg}^{-1}$ below $-100 \mathrm{~J} \mathrm{~kg}^{-1}$ ) with 900 -hPa wet composite daily averaged wind vectors overlaid (reference vector displayed in the top-right corner of each panel). Data are from the ERA-Interim, composited based on pluviograph data at (a) MP and (b) RF.

controlling the precipitation at the coast are different from those inland.

Although the vector wind difference plots (Figs. 6c,f) show an increase in the onshore component of the wind in the wet composites, which is accompanied by and increase in CAPE (Fig. 7), this does not necessarily mean that moisture is transported from the adjacent ocean into the region of interest. The history of air parcels and their relationship to the composite states is assessed using back trajectories on various pressure levels, based on the composite wind fields. Figure 8 shows 7-day isobaric back trajectories from MP and RF in using the respective wet and dry composite winds. In each case, the relevant composite winds are imposed for 7 days and the paths of air parcels that arrive over the BOM pluviograph sites at the final time step are examined. In this calculation the composite diurnal cycle is maintained and vertical motion is not included as the mean values are very small.

Figures $8 \mathrm{a}$ and $8 \mathrm{~b}$ show that for air parcels arriving over MP, the composite trajectories are similar at all pressure levels. During both wet and dry conditions the air parcels below $850 \mathrm{hPa}$ originate from over the Indian Ocean to the west, while air parcels above this level originate predominantly from the east. The main differences are that the trajectories that arrive from the east originate closer to the equator in the wet composites (in the tropics rather than the subtropics). At RF (Figs. 8c,d), the differences between back trajectories in the wet and dry composites are much greater; although the paths of air parcels in the mid- and upper troposphere (above $500 \mathrm{hPa}$ ) are broadly similar, there is a clear difference in the trajectories at the lowest levels. When rain falls at RF (Fig. 8d), the trajectories at the lowest levels $(>700 \mathrm{hPa})$ show that air originates from the nearby tropical regions close to the Gulf of Carpentaria and the Cape York Peninsula. In the RF Dry composite (Fig. 8c), the low-level air parcels have more continental trajectories. Overall, this analysis demonstrates that at both sites convection is preceded by a change in the origins and trajectories of air parcels in the lower troposphere from continental subtropical toward tropical maritime. This shift in origin and the anticipated characteristics of the original air masses is consistent with the observed increase in convection and rainfall.

Because previous studies of the long-term trends in the regional rainfall (e.g., Shi et al. 2008) have suggested that these changes are instigated by regional SST variability, the SST observations are considered also. Wet and dry composites of the NOAA SST analysis are constructed using the method applied earlier to the ERA-I data. The resulting SST differences between the wet and dry SST composites at the MP and RF sites are displayed in Fig. 9. As expected from the characteristic time scales of the rainfall events (see Fig. 4) and SST variation, the magnitudes of the differences between each case are relatively small (less than $0.5^{\circ} \mathrm{C}$ ). While weak, the SST difference patterns are large scale and broadly consistent with the atmospheric fields discussed previously. Although the results are relatively noisy in the case of MP (Fig. 9a), there are positive differences in the SST along the coastline in the immediate vicinity of the site and negative differences along the western coast of the Australian continent. This local pattern is consistent with increased rainfall at the coast because, at the local (sea breeze) scale, higher SSTs increase the moist static energy of air parcels in the boundary layer advected onshore and, consequently, increase the probability of convection by altering the thermodynamic profile of the boundary layer. The SST difference for RF (Fig. 9b) is very different to that at MP, where the pattern is dominated by a large-scale region of cooler water along the western coast of Australia and a large-scale region of warmer water along the eastern coast. To the extent that 

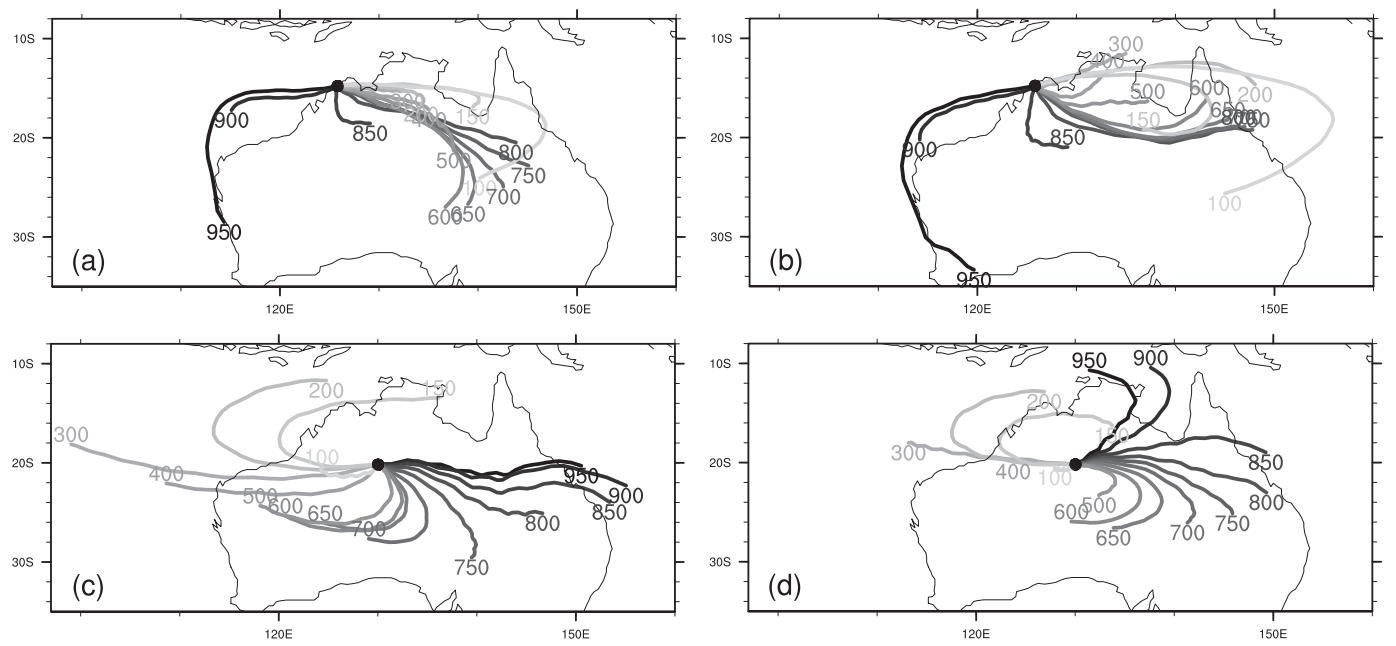

FIG. 8. Idealized 7-day isobaric back trajectories in ERA-I dataset, starting at MP using the (a) dry and (b) wet composites and at RF using the (c) dry and (d) wet composites. Isobaric level (hPa) is denoted by the label at the trajectory start and each path is shaded according to its level, with darker grayscale indicating higher pressure. The locations of the two BOM pluviograph sites are indicated by the filled circles.

the strength of the monsoon and sea breeze circulations vary with the land-ocean surface temperature contrasts, and given the same land surface conditions, the SST pattern in Fig. 9b would enhance the heat low center to the west of RF, which is broadly consistent with the atmospheric fields shown in Fig. 6. Warmer SSTs are noted in the Coral Sea, close to the origin of several low-level wet composite trajectories shown in Fig. 8d, consistent with the increase in CAPE noted previously.

The key point from this figure is the distinct lack of patterns resembling known regional climate modes (e.g., the Indian Ocean dipole (Risbey et al. 2009). Even though there is a clear difference in the time scale of SST and rainfall fluctuations, it is reasonable to expect that if a regional SST pattern were a primary influence on the rainfall over NWA, this pattern would be evident in the averages of several hundred individual cases. Instead, the SST differences between the wet and dry composites are small and show greater consistency with changes in the synopticscale flow than an ocean basin-scale difference in the SST.

\section{Discussion}

The results presented above indicate that there is a distinct change in the diurnal behavior of rainfall from coastal to inland locations in NWA. The signal is
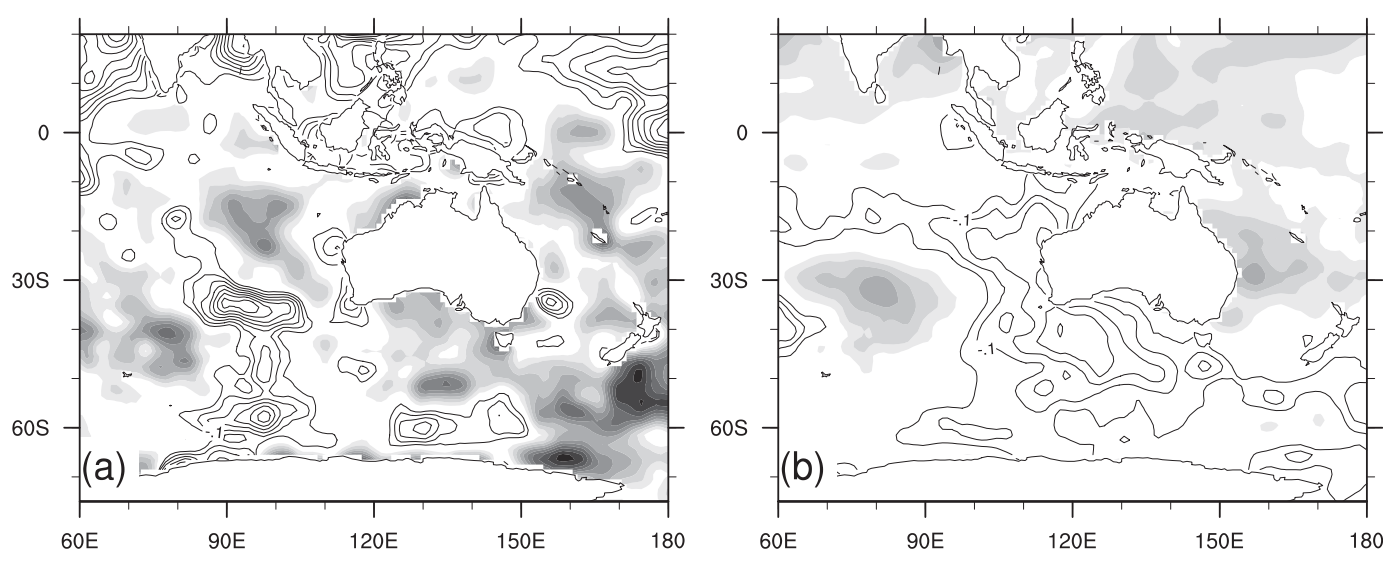

$\begin{array}{llllllllll}0.05 & 0.1 & 0.15 & 0.2 & 0.25 & 0.3 & 0.35 & 0.4 & 0.45 & 0.5\end{array}$

FIG. 9. Difference in NOAA OI SSTs $\left({ }^{\circ} \mathrm{C}\right)$ between the wet and dry composites based on pluviograph data at (a) MP and (b) RF. Positive values greater than $0.05^{\circ} \mathrm{C}$ are shaded according to the legend under the panels and negative values less than $-0.05^{\circ} \mathrm{C}$ are contoured every $0.05^{\circ} \mathrm{C}$. 
considered robust as it is found in two independent datasets - one based on in situ measurements, the other on satellite records. Broadly, the rainfall rates peak in the local afternoon near the coast and overnight in the interior with some evidence of a transition or combination in between (see e.g., Figs. 3a,c). In common with the observations in most continental regions in the tropics, the afternoon peak slightly lags the peak in the solar heating (Yang and Slingo 2001). The inland nocturnal peak is less frequently noted in the existing literature. Other comparable overnight maxima tend to be associated with long-lived organized convective systems as they propagate from their source regions. Well-known examples of this behavior being West African monsoon convection (Hodges and Thorncroft 1997) and the warm season U.S. central plains (Carbone et al. 2002). It is unlikely that the inland overnight peak in rainfall can be attributed to the coherent propagation of convective systems; it has been shown by Pope et al. (2008) that there is not a significant mesoscale convective system (MCS) genesis region upstream of the region of this study. Additionally, the most intense MCSs are generally found close to the coast (Mohr and Zipser 1996). In the context of northern Brazil, Kousky (1980) demonstrated that an inland nocturnal peak in rainfall was related to the interaction of land-sea and mountain-valley circulation moving in opposite directions at low levels and forcing convergence. The same explanation is not true in NWA; as demonstrated by Arnup and Reeder (2007), the nocturnal flow converges into the center of the heat low, but as shown in this study, this convergence alone is not sufficient to initiate convection (see Fig. 5).

At MP, the CAPE field (Fig. 7a) shows only minor differences between the wet and dry composites. On one hand, this result might have been expected as MP lies within the monsoon environment, which is characterized by relatively high $\mathrm{CAPE}$ and the resultant frequent convective systems and large rainfall rates (Fig. 1a). On the other hand, as seen in Figs. 6 and 8 it is evident that there is a definite synoptic-scale difference between wet and dry periods at MP that are not related (directly) to the active and inactive phases of the monsoon (Drosdowsky 1996), and that the precipitation depends on the direction of the large-scale flow toward this location. Nonetheless, integrated quantities such as CAPE are unlikely to fully explain the details of the rainfall and processes on scales smaller than can be resolved in the ERA-I dataset are required to complete the picture. At the mesoscale, a shift in the environmental thermodynamics and flow may alter the characteristics of convection by producing more propagating squall lines upstream or alter the paths of those that exist. Similarly, at the local scale the difference in flow may alter the topographical forced circulations since MP is located on sloping terrain and near complex coastline (see Fig. 2a). Because of a lack of data on the mesoscale, the primary factor governing the rainfall here remains unknown.

Overall, the most important ingredients for the initiation of rainfall in the region of RF, which lies close to the region of the highest observed rainfall trend, appear to be the supply of adequate moisture and instability by the synoptic flow. An obvious question related to this result is the following: what causes the changes to the synoptic pattern supplying to moisture to the interior region? Suppiah (1992) noted that there was strong dayto-day variability in the intensity and location of the heat low in NWA but did not comment on mechanisms responsible for this. The results presented here show that events on synoptic (2-5 day) time scales contribute significantly to the total rainfall (Fig. 4). The ERA-I composites show structures that have synoptic spatial scales $(1000-5000 \mathrm{~km})$. Taken together these results suggest that the changes in the synoptic pattern could be connected to transient synoptic weather systems. Using infrared imagery from geostationary satellites, Kuhnel (1990) compiled a climatology of tropical-extratropical cloud bands over Australia and noted that during the warm season (November-April) cloud bands frequently originated over the ocean adjacent to the BOM sites used in the present study. He also linked these extended cloud bands to cross-equatorial cold surges and the development of the Australian monsoon. Evidence for such features is found in the ERA-I composites when the difference in the midlevel atmospheric structure between wet and dry conditions is examined.

Figure 10 displays the difference in $500-\mathrm{hPa}$ geopotential heights and wind vectors between the wet and dry composites at RF, this time including latitudes farther poleward. It is very clear in this figure that prior to rainfall episodes at RF there is a synoptic-scale region of significantly lower heights centered to the south of Tasmania and increased heights centered off the southwestern tip of the Australian continent. There is also an extension of lower heights across the Great Australian Bight toward NWA, with RF located along its eastern flank. This pattern is consistent with a midlatitude cyclone over southeastern Australia and a cloud band extending well into the tropics (cf. Wright 1997; Knippertz and Martin 2005). Some observational evidence for a summertime tropical-extratropical connection was noted by the analysis of Hung and Yanai (2004) as well as Keenan and Carbone (2008), who remarked that the lack of vertical wind shear and steering winds provided by transient synoptic-scale forcings "can severely limit the potential for long-lived (rainfall) events" over the subtropical $\left(20^{\circ}-30^{\circ} \mathrm{S}\right)$ regions of Australia. 


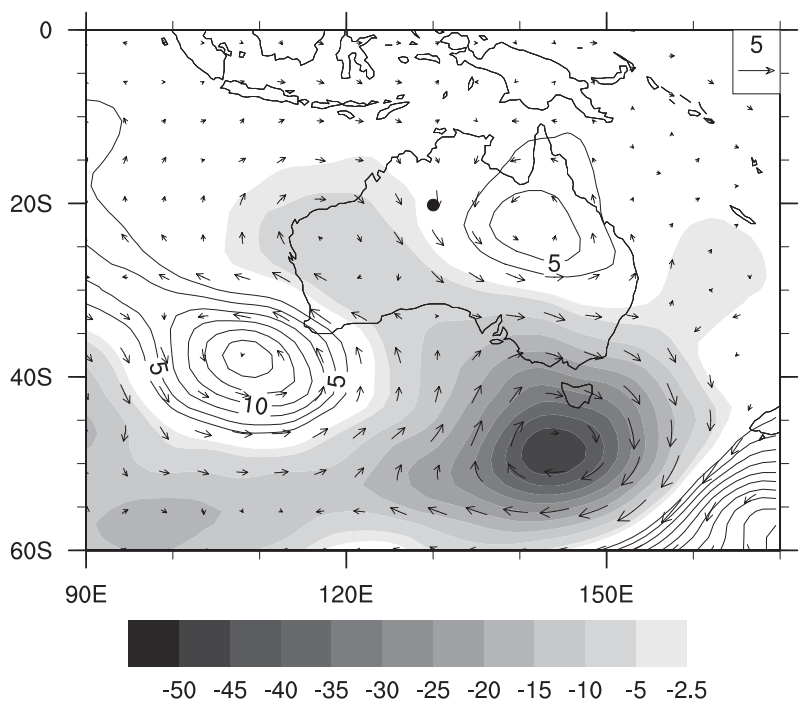

FIG. 10. Difference in 500-hPa geopotential heights $(\mathrm{m})$ and winds $\left(\mathrm{m} \mathrm{s}^{-1}\right)$ in ERA-Interim between wet and dry composites, generated using pluviograph data at RF. Negative geopotential height differences are shaded according to legend and positive height differences greater than $2.5 \mathrm{~m}$ are contoured every $2.5 \mathrm{~m}$. Wind reference vector is shown in the top-right corner.

In addition to extratropical synoptic transients, previous studies have highlighted the tropical weather systems in this region that may affect the moisture supply. In particular, monsoon depressions (Zhao and Mills 1991; Hell and Smith 1998) can significantly affect the local flow and trigger convection in the interior of the continent. Another consideration is the passage of coherent tropical waves propagating through the Australian monsoon altering the synoptic conditions. Wheeler and Kiladis (1999) showed that the outgoing longwave radiation (OLR) variance accompanying the passage of $n=1$ equatorial Rossby waves is similar to the Madden-Julian oscillation (MJO) over northern Australia during austral summer. Using satellite data, the organization of convection by these types of disturbances has been documented by Keenan and Carbone (2008). These results imply that transient tropical disturbances can either directly contribute to the rainfall as they move through the region or can indirectly influence the rainfall through their interaction with the heat low and subsequent alteration of the low-level flow. Further analysis of the role of these phenomena is beyond the scope of this paper.

\section{Conclusions}

Motivated by a large positive trend in the observed summertime rainfall in NWA, this study has explored the underlying physical mechanisms regulating rainfall in this region. This has been accomplished using a combination of pluviographs, remote sensing rainfall estimates, SST observations, and global reanalysis products. It has been shown that there is a distinct diurnal variation in the rainfall at the BOM sites, with peak rainfall rates during midafternoon close to the coast and overnight at locations inland. The diurnal cycles calculated from the TRMM 3B42 rainfall estimates at the grid points closest to the BOM sites were found to be consistent with those derived from the pluviographs, lending additional confidence in the station data and allowing the spatial pattern of the rainfall to be analyzed further. It was found that the region in which the rain falls predominantly at night closely matches the region in which the positive trends are largest, which is approximately in the center of the continental heat low. This result highlights the importance of understanding the fundamental processes before the trends can be explained.

ERA-I composites have shown that the low-level convergence and rainfall vary in phase at all of the locations examined. However, comparison of low-level convergence during precipitating and nonprecipitating periods reveals that the magnitude is practically identical in both instances. This implies that while driving the diurnal phase of rainfall, low-level convergence into the heat low cannot account for its occurrence. One of the key findings here is that the regulation of the low-level moisture by the synoptic-scale flow is the most likely factor determining the occurrence of rainfall within the region of maximum rainfall trends (i.e., within the heat low). The composite structures indicate that prior to rain falling in the heat low region there is a shift in the origin of the air parcels below $700 \mathrm{hPa}$ toward maritime tropical rather than continental subtropical areas, which is brought about by an intensification of the heat low center to the west of the BOM sites. This change in the low-level flow advects relatively warm, moist air from around the Gulf of Carpentaria into the heat low, which increases the CAPE by up to $1500 \mathrm{~J} \mathrm{~kg}^{-1}$. The low-level convergence accompanying the diurnal cycle of the heat low triggers convection in this unstable air mass. It is somewhat counterintuitive that the Gulf of Carpentaria is the source of the moist air participating in the convection over NWA, as the moisture in a monsoon system may be expected to come from the adjacent ocean. This is probably the reason why previous studies addressing the trend have focused on the state of the Indian Ocean (e.g., Shi et al. 2008). These results imply that such remote regions must also be considered in future studies that attempt to explain the rainfall trend in NWA.

Based on the precipitation records at the BOM sites and the ERA-I composites, it was shown that the changes in the structure of the heat low and the origins of air parcels occur on synoptic temporal and spatial scales. This suggests that the forcing for these changes 
could be tropical and extratropical weather systems, such as monsoon lows and midlatitude cyclones. The mechanisms presented here should be further examined to fully explain the observed rainfall trends in NWA. Further work is needed to determine the nature of these external influences, particularly their relative importance and frequency. To explain the trend in rainfall over NWA, consideration may be given to ascertaining if more rainfall events occur because the moisture associated with each event is increasing or if there is larger moisture transport by the external influences.

Acknowledgments. The authors would like to acknowledge the contribution of Jonathon Louey-Gung, who conducted some of the preliminary analysis used in this study. Pluviograph data were provided by the Australian Bureau of Meteorology, TRMM data were provided by NASA, and ERA-Interim data were obtained from the European Centre for Medium-Range Weather Forecasts. This study is supported by the Australian Research Council through Linkage Project Grant LP0883961 and DP0985665 "Rainfall over the Maritime Continent and Northern Australia."

\section{REFERENCES}

Arnup, S. J., and M. J. Reeder, 2007: The diurnal and seasonal variation of the northern Australian dryline. Mon. Wea. Rev., 135, 2995-3008.

- and - 2009: The structure and evolution of the northern Australian dryline. Aust. Meteor. Oceanogr. J., 58, 215-231.

Carbone, R. E., J. D. Tuttle, D. A. Ahijevych, and S. B. Trier, 2002: Inferences of predictability associated with warm season precipitation episodes. J. Atmos. Sci., 59, 2033-2056.

Drosdowsky, W., 1996: Variability of the Australian summer monsoon at Darwin: 1957-1992. J. Climate, 9, 85-96.

Hall, N., and P. Peyrille, 2006: Dynamics of the West African monsoon. J. Phys. IV, 139, 85-103.

Hell, R., and R. K. Smith, 1998: A monsoon depression over northwestern Australia part I: Case study. Aust. Meteor. Mag., 47, 21-40.

Hendon, H. H., and B. Liebmann, 1990: A composite study of onset of the Australian summer monsoon. J. Atmos. Sci., 47, 2227-2240.

Hodges, K. I., and C. D. Thorncroft, 1997: Distribution and statistics of African mesoscale convective weather systems based on the ISCCP Meteosat imagery. Mon. Wea. Rev., 125, 2821-2837.

Huffman, G. J., and Coauthors, 2007: The TRMM multi-satellite precipitation analysis: Quasi-global, multi-year, combined-sensor precipitation estimates at fine scale. J. Hydrometeor., 8, 28-55.

Hung, C.-W., and M. Yanai, 2004: Factors contributing to the onset of the Australian summer monsoon. Quart. J. Roy. Meteor. Soc., 130, 739-758

Keenan, T. D., and R. E. Carbone, 2008: Propagation and diurnal evolution of warm season cloudiness in the Australian and maritime continent region. Mon. Wea. Rev., 136, 973-994.

Knapp, K. R., M. C. Kruk, D. H. Levinson, and E. J. Gibney, 2009: Archive compiles new resource for global tropical cyclone research. Eos, Trans. Amer. Geophys. Union, 90, doi:10.1029/ 2009EO060002.
Knippertz, P., and J. E. Martin, 2005: Tropical plumes and extreme precipitation in subtropical and tropical West Africa. Quart. J. Roy. Meteor. Soc., 131, 2337-2365.

Kousky, V. E., 1980: Diurnal rainfall variation in northeast Brazil. Mon. Wea. Rev., 108, 488-498.

Kuhnel, I., 1990: Tropical-extratropical cloudbands in the Australian region. Int. J. Climatol., 10, 341-364.

Lavery, B., A. Kariko, and N. Nicholls, 1992: A historical rainfall data set for Australia. Aust. Meteor. Mag., 40, 33-39.

McBride, J. L., and T. D. Keenan, 1982: Climatology of tropical cyclone genesis in the Australian region. J. Climatol., 2, 13-33.

Mohr, K. I., and E. J. Zipser, 1996: Mesoscale convective systems defined by their $85-\mathrm{GHz}$ ice scattering signature: Size and intensity comparison over tropical oceans and continents. Mon. Wea. Rev., 124, 2417-2437.

Pope, M., C. Jakob, and M. J. Reeder, 2008: Convective systems of the north Australian monsoon. J. Climate, 21, 5091-5112.

Racz, Z., and R. K. Smith, 1999: The dynamics of heat lows. Quart. J. Roy. Meteor. Soc., 125, 225-252.

Reynolds, R. W., N. A. Rayner, T. M. Smith, D. C. Stokes, and W. Wang, 2002: An improved in situ and satellite SST analysis for climate. J. Climate, 15, 1609-1625.

Risbey, J. S., M. J. Pook, P. C. McIntosh, M. C. Wheeler, and H. H. Hendon, 2009: On the remote drivers of rainfall variability in Australia. Mon. Wea. Rev., 137, 3233-3253.

Rotstayn, L. D., and Coauthors, 2007: Have Australian rainfall and cloudiness increased due to the remote effects of Asian anthropogenic aerosols? J. Geophys. Res., 112, D09202, doi:10.1029/2006JD007712.

Shi, G., W. Cai, T. Cowan, J. Ribbe, L. Rotstayn, and M. Dix, 2008: Variability and trend of northwest Australia rainfall: Observations and coupled climate modeling. J. Climate, 21, 2938-2959.

Smith, I. N., 2004: An assessment of recent trends in Australian rainfall. Aust. Meteor. Mag., 53, 163-173.

Spengler, T., M. J. Reeder, and R. K. Smith, 2005: The dynamics of heat lows in simple background flows. Quart. J. Roy. Meteor. Soc., 131, 3147-3165.

Suppiah, R., 1992: The Australian summer monsoon: A review. Prog. Phys. Geogr., 16, 283-318.

Tarpley, J. D., S. R. Schneider, and R. L. Money, 1984: Global vegetation indices from the NOAA-7 meteorological satellite. J. Climate Appl. Meteor., 23, 491-494.

Taschetto, A. S., and M. H. England, 2008: An analysis of late 20th Century trends in Australian rainfall. Int. J. Climatol., 29, 791807, doi:10.1002/joc.1736.

Taylor, C. M., and T. Lebel, 1998: Observational evidence of persistent convective-scale rainfall patterns. Mon. Wea. Rev., 126,1597-1607.

Wardle, R., and I. Smith, 2004: Modeled response of the Australian monsoon to changes in land surface temperatures. Geophys. Res. Lett., 31, L16205, doi:10.1029/2004GL020157.

Wheeler, M., and G. N. Kiladis, 1999: Convectively coupled equatorial waves: Analysis of clouds and temperature in the wavenumber-frequency domain. J. Atmos. Sci., 56, 374-399. and J. L. McBride, 2005: Australian-Indonesian monsoon. Intraseasonal Variability in the Atmosphere-Ocean Climate System, W. K. M. Lau and D. E. Waliser, Eds., Praxis, 125-173.

Wright, W. J., 1997: Tropical-extratropical cloudbands and Australian rainfall: I. Climatology. Int. J. Climatol., 17, 807-829.

Yang, G. Y., and J. Slingo, 2001: The diurnal cycle in the Tropics. Mon. Wea. Rev., 129, 784-801.

Zhao, S., and G. A. Mills, 1991: A study of a monsoon depression bringing record rainfall over Australia. Part II: Synoptic diagnostic description. Mon. Wea. Rev., 119, 2074-2094. 